\title{
Possible interrelation between the lead time of precursory seismic electric signals (SES) and geodynamics in Aegean Sea
}

\author{
E. Dologlou \\ Solid State Section, Department of Physics, University of Athens, Greece \\ Received: 26 October 2010 - Accepted: 3 March 2011 - Published: 6 June 2011
}

\begin{abstract}
The seismicity of the last 15 years in the Aegean Sea revealed that earthquakes $\left(M_{\mathrm{w}}>5\right)$ with epicentres falling within the Sporades basin and the confined area north of Samos island were preceded by electric seismic signals (SES) with a remarkably long lead time. A possible explanation of this behaviour by means of specific tectonics and geodynamics which characterise these two regions, such as a significant small crustal thickness and a high heat flow rate, has been attempted. New data seem to strengthen the above hypothesis.
\end{abstract}

\section{Introduction}

In the last 25 years transient changes of low frequency of the Earth's telluric field, known as Seismic Electric Signals (SES), have been found to precede large earthquakes in Greece (Varotsos and Alexopoulos, 1984a, b; Varotsos et al., 1993b). The most important features of the SES signals are the selectivity effect and the lead time. The selectivity which contributes to the determination of the epicentre of the forthcoming earthquake, states that a SES station can be sensitive to some specific areas and remain inactive to others even at closer distances (Varotsos and Lazaridou, 1991; Varotsos et al., 1993a). The lead time, $\Delta \mathrm{t}$, which is the time difference between the occurrence of the earthquake and the detection of its associated SES signal, can vary from some hours (for a single signal) to some weeks (for SES activity). A better approximation (of the order of a few days) of the time of the impending earthquake has been recently achieved by the introduction of a new time concept, termed natural time, (Varotsos et al., 2002; 2003a, b; 2005a, b) which considers the order evolution of events (i.e. 1st, 2 nd, etc.) instead of

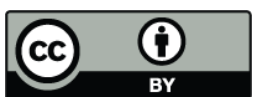

Correspondence to: E. Dologlou (edologl@phys.uoa.gr) the conventional time evolution. It was shown (Abe et al., 2005) that in this time-domain the maximum information is extracted from a given time-series.

Many studies on the possible correlation between SES features and associated earthquake parameters have been elaborated and some interesting results occurred. For instance, the selectivity property (Varotsos et al., 1986; Varotsos and Alexopoulos, 1987) is found to be affected by tectonics as, for example, the mountain chain of Hellenides running through mainland-Greece in a NW-SE direction acts as a natural barrier to the SES propagation. That means that all SES stations located in western Greece cannot "see" the candidate seismic focal areas in the east and vice-versa (Varotsos and Lazaridou, 1991). On the other hand, a promising power-law relation between the SES lead time and the stress drop of the forthcoming earthquake with an exponent falling within the range of critical values for fracture, has been found (Dologlou, 2008a, b, 2009, 2010). The lead time also seems to be related to tectonics and geodynamics. A recent study (Dologlou et al., 2008) revealed that large $(M>5)$ earthquakes in the Aegean Sea, preceded by SES with an appreciably long lead time, occurred only in specific, confined regions with a remarkably small crustal thickness and a high heat flow (Le Pichon et al., 1984; Makris et al., 2001; Jongsma, 1974).

It is of interest and the scope of the present paper to check whether the above-mentioned preliminary dependence findings of the SES long lead time on specific geotectonics is consistent when new data are considered.

\section{Tectonics and geodynamics in the Aegean Sea}

Currently, many models have been proposed to explain the complex deformation styles and the active tectonics of the Aegean Sea applying different geophysical methods, GPS measurements, palaeomagnetic studies, field observations

Published by Copernicus Publications on behalf of the European Geosciences Union. 
and focal mechanisms of earthquakes. The complexity of the geodynamic regime is a result of the combined actions of the convergence of the African-Eurasian plates and the westward motion of the Anatolian plate relative to Europe which renders the Aegean Sea one of the most seismically active regions of Europe.

In the south, the subducting African slab forms a Benioff zone dipping northward at two different angles of $35^{\circ}$ and $15^{\circ}$, respectively, as depicted by seismicity (McKenzie, 1972; Le Pichon and Angelier, 1981; Walcott and White, 1998; Christova and Nikolova, 1993). On the other hand, the westward motion of the Anatolian plate relative to Europe creates the North Anatolian transform right lateral fault (NAF) which extends westward and penetrates the north part of the Aegean Sea splitting into parallel faults (McKenzie, 1972; Taymaz et al., 1991; Armijo et al., 1996; Doglioni et al., 2002).

The Aegean Sea is generally considered as a backarc basin due to the subduction (Le Pichon and Angelier, 1979). However, according to Makris (1978) and Makris et al. (2001), it is mainly characterised by a relatively thick crust in spite of a long standing subduction, probably active since Cretaceous times (Meulenkamp et al., 1988). Most of the seismicity is rather superficial and the high geothermic gradient is probably responsible for the seismic disappearance of the slab underneath the basin.

The central Aegean has high heat flow, approximately three times higher than the surrounding eastern Mediterranean. It exhibits positive Bouguer and magnetic anomalies and is dominated by extensional tectonics with north-east and south-east trending faults (Jongsma, 1974; Le Pichon and Angelier, 1979; Makris, 1978; McKenzie, 1978).

In the western part, the Sporades basin containing a thick sequence of late Cenozoic sediments, coincides with a zone of extreme lithospheric stretching and the crustal thickness is locally reduced to only $15 \mathrm{~km}$ (Le Pichon et al., 1984). On the other hand, deep seismic sounding measurements across the Malliakos-Sporades basin (Makris et al., 2001) showed that the transition of the Maliakos-Evia continental block to the thinned continental crust of the Sporades Basin with the thick sediments that cover it, most probably delineates an ancient border of a passive margin developed along the Servo-Macedonian massive, presently compressed and crust-shortened between the Evia-Pilion unit, and the ServoMacedonian massive.

The normal and the strike-slip earthquake mechanisms mainly dominate in the Aegean Sea; in the western part (including a zone of the mainland) extensional stress expressed by normal faulting and T-axes trending NNW-SSE (Kiratzi and Louvari, 2003) and in the central and eastern Aegean, right lateral strike-slip faults trending in NE-ENE (Kiratzi et al., 1991; Armijo et al., 1996; Kiratzi and Louvari, 2003).

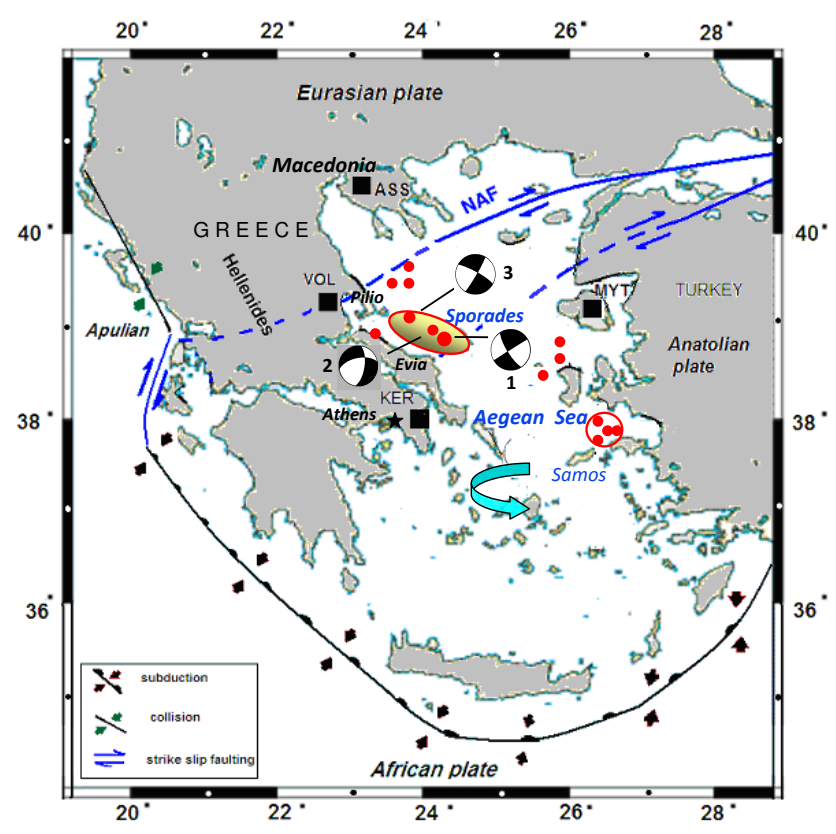

Fig. 1. Geotectonic map of Greece with all epicentres (red solid circles) of earthquakes of $M \mathrm{w} \geq 5$ occurred from 1 January 1995 to 20 October 2010 in the Aegean Sea between the latitudes (37$40)^{\circ} \mathrm{N}$. CMT fault plane solutions are given only for the events located in the Sporades basin (shaded ellipse). A lower hemisphere projection is used with black and white quadrants (beach balls) for compression and dilatation, respectively. Numbers attached refer to the events in Table 1. The red open circle denotes the Samos cluster while black squares the positions of the VAN-SES stations sensitive to Aegean Sea.

\section{Data and analysis}

Among the various stations of the telemetric SES network, four have been found to be sensitive to the Aegean Sea (Fig. 1-solid black squares); the ASS station in the north, which mainly covers the northern Aegean, the MYT station in the east, close to the coast of Anatolia-Turkey, that mostly "sees" the eastern part of the Aegean, the VOL station in central Greece and the KER station close to Athens, both of which are sensitive to western and central Aegean. MYT and KER stations started operating some years later than the other two.

From 1 January 1995 to 18 October 2010, fourteen earthquakes with moment magnitude $M_{\mathrm{w}} \geq 5$ occurred in the Aegean Sea between the latitudes $(37-40)^{\circ}$ N. (Fig. 1 red solid circles). According to their Centroid moment solutions (CMT-Harvard), all of them were of a strike-slip type mechanism, as it was expected, since they occurred along the extension of the North Anatolian Fault (NAF) or on a parallel fault system.

From these fourteen events, three had an epicentre falling in the restricted area of the Sporades basin while the other four events were clustered north of Samos island close to 
Table 1. All PDE reported earthquakes with $M_{\mathrm{w}} \geq 5$ for the period 1 January 1995 to 18 October 2010, that occurred within the Sporades basin in the Aegean Sea along with their CMT solutions and characteristics of corresponding SES (time, station (STN) of detection and lead time, $\Delta \mathrm{t}$ ).

\begin{tabular}{|c|c|c|c|c|c|c|c|c|c|c|c|c|c|}
\hline & & & & EQ & & & & & & & SES & & \\
\hline no & yy $\mathrm{mm}$ dd & $\mathrm{H}$ & MIN & $\mathrm{S}$ & LAT & LONG & depth & $\begin{array}{l}M_{W} \\
\text { (HRV) }\end{array}$ & CMT & COMMENT & yy mm dd & STN & $\begin{array}{l}\Delta \mathrm{t} \\
\text { (days) }\end{array}$ \\
\hline 1 & 010726 & 00 & 21 & 36.92 & 39.06 & 24.24 & 10 & 6.5 & strike-slip & SPORADES & 010317 & VOL & 161 \\
\hline 2 & 010730 & 15 & 24 & 56.74 & 39.09 & 24.04 & 10 & 5.0 & strike-normal & aftershock & 010317 & VOL & 161 \\
\hline 3 & 100716 & 18 & 53 & 10.4 & 39.31 & 23.99 & 10 & $5.1^{*}$ & strike-slip & SPORADES & 100225 & KER & 141 \\
\hline
\end{tabular}

${ }^{*} \mathrm{M}_{\mathrm{W}}$ adopted from EMSC since $\mathrm{M}_{\mathrm{W}}$ Harvard was not available for this event.

the coast of Turkey (Fig. 1 - shaded ellipse and red open circle, respectively). All except three main earthquakes (with $M_{\mathrm{w}} 5.0-5.1$ ), were preceded by a reported SES signal (Varotsos, 2005; Varotsos et al., 2006a, b; 2010) with lead time, $\Delta t$, values falling into two groups; one of short lead time (27-53 days) and another with a much longer lead time (141-212 days). Only earthquakes with epicentres located either in the Sporades basin or in the Samos cluster have been found to be associated with SES of long lead time. All SES were detected either at MYT or VOL station and only one in KER, while no event was detected by ASS station.

In this work, we restrict ourselves to the earthquakes located in the Sporades basin including the last one which occurred on 16 July 2010, since the other events were discussed in detail in a previous paper (Dologlou et al., 2008). Their seismic parameters (dates, epicentres), moment magnitudes $M_{\mathrm{w}}$, source mechanism type (strike-slip, normal or thrust) based on Harvard CMT solutions and SES parameters (time of detection, station and lead time $\Delta \mathrm{t}$ ), are listed in Table 1 .

\section{Discussion}

Our experience revealed that SES associated with earthquakes located in the Sporades basin are characterised by remarkably long lead times. It is interesting to check whether a new earthquake with an epicentre falling inside this confined area of the Sporades basin or in the Samos cluster (Fig. 1 shaded ellipse and red open circle, respectively) will also be preceded by a long lead time SES signal. Indeed, after the occurrence of the $M_{\mathrm{w}}=6.5$ and its aftershock $M_{\mathrm{w}}=5$ earthquakes on 26 and 30 July 2001, respectively (Table 1, events no. 1 and 2), the next event with the epicentre inside the Sporades basin was the $M_{\mathrm{w}}=5.1$ earthquake that took place on 16 July 2010 (Table 1 event no. 3). It was preceded by an SES recorded at KER station (Fig. 1) on 25 February 2010 with a long lead time $\Delta t=141$ days. We note that up to now, no new earthquakes occurred within the Samos cluster.

Let us now examine, in terms of physics, whether a possible interrelation between SES lead time and geodynamics can be justified. A proposed model (Varotsos et al., 1998; Varotsos and Alexopoulos, 1986) for the SES generation is given below:

In an ionic solid, the electric dipoles formed between introduced aliovalent impurities (Varotsos, 1976; Varotsos and Alexopoulos, 1978, 1979) and vacancies (Varotsos and Alexopoulos, 1984c) created for charge compensation (Varotsos, 2007; Varotsos and Alexopoulos, 1982; Kostopoulos et al., 1975) can change the orientation upon increasing pressure, giving rise to a transient current, called piezostimulated current (PSC). The relaxation time, $\tau$, of these dipoles is given by the relation

$\tau=(\lambda \nu)^{-1} \exp (\mathrm{g} / \mathrm{k} T)$

where $T$ is the temperature, $v$ is the attempt frequency for a jump to a number of $\lambda$ accessible paths in the vacancy vicinity, $g$ the Gibbs energy for the orientation process and $\mathrm{k}$ the Boltzmann constant.

Before an earthquake, the tectonic stress (pressure) gradually increases in the future focal area with a rate $b(=\mathrm{dP} / \mathrm{dt})$. When the pressure reaches a critical value, $P_{\mathrm{cr}}$, a transient current, due to a cooperative orientation of dipoles which exist in ionic crystals in rocks, known as SES, is emitted and the following relation (if an increase in pressure results in a decrease of relaxation time) holds (Varotsos, 1977; Varotsos and Alexopoulos, 1980):

$\frac{b v}{\mathrm{k} T}=-\frac{1}{\tau\left(P_{\mathrm{cr}}\right)}$

where $\tau\left(P_{\mathrm{cr}}\right)$ is the value of relaxation time at $P=P_{\mathrm{cr}}$ (Varotsos and Alexopoulos 1986; Varotsos, 1977). The increase of the pressure (stress) continues until the fracture stress $P_{\mathrm{fr}}$ is reached where the failure of the solid and consequently the earthquake occurs. Therefore, the emission of this transient current (e.g., SES) can be considered as a precursor to the fracture of a solid (e.g., earthquake). The lead time $\Delta \mathrm{t}$ between the emission of the SES and the impending earthquake is given by

$\Delta t=\left(P_{\mathrm{fr}}-P_{\mathrm{cr}}\right) / b$ 
assuming that the accumulating stress rate $b$ remains constant during the last preparatory stage before the fracture (earthquake). In contrast, the appearance and the emission of the SES is independent of the stability of $b$ (Varotsos, 2005).

From Eqs. (1) and (3), derives (Varotsos et al., 1993a)

$d P_{\mathrm{cr}} / d b\left(P_{\mathrm{cr}}\right)=\tau\left(P_{\mathrm{cr}}\right)$

which shows that $\mathrm{d} P_{\mathrm{cr}} / \mathrm{db}\left(P_{\mathrm{cr}}\right)$ is always positive. Therefore, smaller values of $\mathrm{b}$ leads to also smaller values of the critical pressure $P_{\text {cr }}$ implying that the numerator of the right side of Eq. (3) becomes larger. Thus, a decrease in the $b$ value causes a two-fold increase in the lead time and vice versa.

The crustal transition of the thinned Sporades Basin to the $30-\mathrm{km}$ thick crust of the northern Evia and the Maliakos Straits is poorly understood (Makris et al., 2001). Simple or pure shear stretching cannot have developed this margin and Makris et al. (2001) favour the assumption that it denotes the limit of two different crustal domains; these were merged together during a compressive tectonic episode, prior to the present-day extension and stretching of the Aegean Sea that was activated 5 Ma ago. Additionally, Le Pichon et al. (1984) report that the Sporades basin, which contains a thick sequence of late Cenozoic sediments, coincides with a zone of extreme lithospheric stretching and the crustal thickness is locally reduced to only $15 \mathrm{~km}$.

These specific geotectonics (i.e., remarkably small crustal thickness) of the Sporades basin possibly affect the accumulating stress rate b, the critical $P_{\mathrm{cr}}$ and fracture $P_{\mathrm{fr}}$ stress in such a manner that their combination in Eq. (3) may justify the observed longer lead time $\Delta \mathrm{t}$. Thus, the hypothesis of Dologlou et al. (2008) that SES lead time might be controlled by geodynamics, seems to be strengthened.

\section{Conclusions}

The seismicity of the last 15 years revealed that in the Aegean Sea, only earthquakes $\left(M_{\mathrm{w}}>5\right)$ with epicentres falling within two restricted areas, the Sporades basin and the Samos cluster, are associated with SES of appreciably long lead times. An effort to justify this behaviour by means of specific tectonics and geodynamics that characterise these two regions, such as remarkably small crustal thickness and high heat flow rate, has been attempted. This hypothesis is further strengthened by the fact that the next new earthquake which occurred in the Sporades basin on 16 July 2010, was also preceded by a long lead time SES.

Edited by: M. E. Contadakis

Reviewed by: two anonymous referees

\section{References}

Abe, S., Sarlis, N. V., Skordas, E. S., Tanaka, H. K., and Varotsos, P. A.: Origin of the usefulness of the natural time representation of complex time series, Phys. Rev. Lett., 94, 170601, 4 pp., 2005.

Armijo, R., Meyer, A., King, G., Rigo, A., and Papanastassiou, D.: Quaternary evolution of the Corinth Rift and its implications for the Late Cenozoic evolution of the Aegean, Geophys. J. Int., 126, 11-53, 1996.

Christova, C. and Nikolova, S. B.: The Aegean region: deep structures and seismological properties, Geophys. J. Int., 115, 635653, 1993.

Doglioni, C., Agostini, S., Crespi, M., Innocenti, F., Manetti, P., Riguzzi, F., and Savasçin, Y.: On the extension in western Anatolia and the Aegean sea, in: Reconstruction of the evolution of the Alpine-Himalayan Orogen, edited by: Rosenbaum, G. and Lister, G. S., Journal of the Virtual Explorer, 8, 161-176, http://virtualexplorer.com.au/, 2002.

Dologlou, E.: Power law relationship between parameters of earthquakes and precursory electrical phenomena, Nat. Hazards Earth Syst. Sci., 8, 977-983, doi:10.5194/nhess-8-977-2008, 2008a.

Dologlou, E.: Possible relationship between Seismic Electric Signals (SES) lead time and earthquake stress drop, Proc. Jpn. Acad., Ser. B, 84, 117-122, 2008b.

Dologlou, E.: Power law relationship between parameters of earthquakes and precursory electrical phenomena revisited, Nat. Hazards Earth Syst. Sci., 9, 17-23, doi:10.5194/nhess-9-17-2009, 2009.

Dologlou, E.: Power law relationship between parameters of earthquakes and precursory electrical phenomena revisited II, Nat. Hazards Earth Syst. Sci., 10, 1403-1409, doi:10.5194/nhess-101403-2010, 2010.

Dologlou, E., Hadjicontis, V., and Mavromatou, C.: Electrical precursors of earthquakes in Aegean Sea during the last decade (1997-2007), Nat. Hazards Earth Syst. Sci., 8, 123-128, doi:10.5194/nhess-8-123-2008, 2008.

Jongsma, D.: Heat Flow in the Aegean Sea, Geophys. J. Int., 37(3), 337-346, 1974.

Kiratzi, A. and Louvari, E.: Focal mechanisms of shallow earthquakes in the Aegean Sea and surrounding lands determined by waveform modelling: a new database, J. Geodyn., 36, 251-274, 2003.

Kiratzi, A., Wagner, G., and Langston, C. A.: Source parameters of some large earthquakes in northern Aegean determined by Body Waveform inversion, Pure Appl. Geophys., 135, 515-527, 1991.

Kostopoulos, D., Varotsos, P. A., and Mourikis, S.: Conductivity of crystalline NaI, Can. J. Phys., 53, 1318-1320, 1975.

Le Pichon, X. and Angelier, J.: The Hellenic arc trench system: a key to the neotectonic evolution of the eastern Mediterranean area, Tectonophysics, 60, 1-42, 1979.

Le Pichon, X. and Angelier, J.: The Aegean Sea, Phil. Trans. R. Soc. Lond., 300, 357-372, 1981.

Le Pichon, X., Lyberis, N., and Alvarez, F.: Subsidence history of North Aegean through in: "The geological evolution of the Eastern Mediterranean", edited by: Dixon, J. and Robertson, A., Geol. Soc. London, SP. Publ. N ${ }^{\circ} 17$, Blackwell Scientif. Pub., Oxford, 727-741, 1984.

Makris, J.: The crust and upper mantle of the Aegean region from deep seismic soundings, Tectonophysics, 46, 269-284, 1978.

Makris, J., Papoulia, J., Papanikolaou, D., and Stavrakakis, G.: 
Thinned continental crust below northern Evoikos Gulf, central Greece, detected from deep seismic soundings, Tectonophysics, 341, 225-236, 2001.

McKenzie, D. P.: Active tectonics of the Mediterranean region, Geophys. J. R. Astron. Soc., 30, 109-185, 1972.

McKenzie, D. P.: Active tectonics of the Alpine - Himalayan belt: Aegean Sea and surroundings regions, Geophys. J. R. Astron. Soc., 55, 217-254, 1978.

Meulenkamp, J. E., Wortel, M. J. R., Van Wamel, W. A., Spakman, W., and Hoogerduyn-Starting, E.: On the Hellenic subduction zone and the geodynamic evolution of Crete since the late Middle Miocene, Tectonophysics, 146, 203-216, 1988.

Taymaz, T., Jackson, J. A., and McKenzie, D.: Active Tectonics of the North and Central Aegean Sea., Geophys. J. Int., 106, 433490, 1991.

Varotsos, P. A.: Comments on the formation entropy of a Frenkel defect in BaF2 and CaF2, Phys. Rev. B: Solid State, 13, 938, 1976.

Varotsos, P. A.: Temperature and pressure dependence of defect formation volume in ionic crystals, J. Phys. (France), 38, L455L458, 1977.

Varotsos, P. A.: On the temperature variation of the bulk modulus of mixed alkali halides, Phys. Status Solidi (b), 99, K93-K96, 1980.

Varotsos, P. A.: The Physics of Seismic Electric Signals, TerraPub, Tokyo, 87-115, 2005.

Varotsos, P. A.: Comparison of models that interconnect point defect parameters, J. Appl. Phys., 101, 123503, doi:10.1063/1.2745359, 2007.

Varotsos, P. A. and Alexopoulos, K.: The curvature in conductivity plots of silver halides as a consequence of anharmonicity, J. Phys. Chem. Solids, 39, 759-761, 1978.

Varotsos, P. A. and Alexopoulos, K.: On the possibility of the enthalpy of a Schottky defect decreasing with increasing temperature, J. Physics C: Solid State, 12, L761-L764, 1979.

Varotsos, P. A. and Alexopoulos, K.: Current methods of lattice defect analysis using dilatometry and self diffusion, Critical Review and proposals, Phys. Stat. Solidi B, 110, 9-31, 1982.

Varotsos, P. A. and Alexopoulos, K.: Physical properties of the variations of the electric field of the earth preceding earthquakes, I, Tectonophysics, 110, 73-98, 1984a.

Varotsos, P. A. and Alexopoulos, K.: Physical properties of the variations of the electric field of the earth preceding earthquakes, II. Determination of epicentre and magnitude, Tectonophysics, 110, 99-125, 1984b.

Varotsos, P. A. and Alexopoulos, K.: Connection between the formation volume and formation Gibbs energy in noble gas solids, Phys. Rev. B, 30, 7305-7306, 1984c.

Varotsos, P. A. and Alexopoulos, K.: Thermodynamics of Point Defects and their Relation with the Bulk Properties, North Holland, Amsterdam, 403-406, 1986.
Varotsos, P. A. and Alexopoulos, K.: Physical properties of the variations in the electric field of the earth preceding earthquakes, III, Tectonophysics, 136, 335-339, 1987.

Varotsos, P. A. and Lazaridou, M.: Latest aspects of earthquake Prediction in Greece based on Seismic Electric Signals, I, Tectonophysics, 188, 321-347, 1991.

Varotsos, P. A., Alexopoulos, K., Nomicos, K., and Lazaridou, M.: Earthquake prediction and electric signals, Nature, 322, 120 130, 1986.

Varotsos, P. A. , Alexopoulos, K., and Lazaridou, M.: Latest aspects of earthquake prediction in Greece based on Seismic Electric Signals II, Tectonophysics, 224, 1-37, 1993a.

Varotsos, P. A., Alexopoulos, K., Lazaridou, M., and Nagao, T.: Earthquake predictions issued in Greece by seismic electric signals since February 6, 1990, Tectonophysics, 244, 269-288, 1993 b.

Varotsos, P. A., Sarlis, N., Lazaridou, M., and Kapiris, P.: Transmission of stress induced electric signals in dielectric media, J. Appl. Phys., 83, 60-70, 1998.

Varotsos, P. A., Sarlis, N. V., and Skordas, E. S.: Long-range correlations in the electric signals that precede rupture, Phys. Rev. E, 66, 011902, 7 pp., 2002.

Varotsos, P. A., Sarlis, N. V., and Skordas, E. S.: Long-range correlations in the electric signals that precede rupture: further investigations, Phys. Rev. E., 67, 021109, 13 pp., 2003a.

Varotsos, P. A., Sarlis, N., and Skordas, E.: Attempt to distinguish electric signals of a dichotomous nature, Phys. Rev. E., 68, 031106, 7 pp., 2003 b.

Varotsos, P. A., Sarlis, N. V., Tanaka, H. K., and Skordas, E. S.: Some properties of the Entropy in natural time, Phys. Rev. E., 71, 032102, 2005a.

Varotsos, P. A., Sarlis, N. V., Skordas, E. S., and Lazaridou, M.: Natural entropy fluctuations discriminate similar looking electric signals emitted from systems of different dynamics, Phys. Rev. E, 71, 011110, 11 pp., 2005b.

Varotsos, P. A., Sarlis, N., Skordas, E., Tanaka, H., and Lazaridou, M.: Entropy of seismic electric signals: analysis in natural time under time reversal, Phys. Rev. E, 73, 031114, 8 pp., 2006 a.

Varotsos, P. A., Sarlis, N., Skordas, E., Tanaka, H., and Lazaridou, M.: Attempt to distinguish long-range temporal correlations from the statistics of the increments by natural time analysis, Phys. Rev. E., 74, 021123, 12 pp., 2006b.

Varotsos, P., Sarlis, N., and Skordas, E.: Effect of significant data loss on identifying electric signals that precede rupture by detrended fluctuation analysis in natural time, arXiv.org $>$ condmat > arXiv:1003.1383v5, 2010.

Walcott, C. and White, S.: Constraints on the kinematics of post-orogenic extension imposed by stretching lineations in the Aegean region, Tectonophysics, 298, 155-175, 1998. 